\title{
Evaluating the Stability and Adequacy of NIGNET for the Definition of Nigerian Geodetic Reference Frame
}

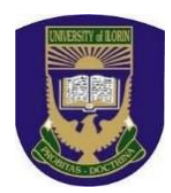

\author{
E. G. Ayodele ${ }^{1}$, C. J. Okolie ${ }^{1 *}$, C. U. Ezeigbo², F. A. Fajemirokun ${ }^{2}$ \\ ${ }^{1}$ Department of Surveying \& Geoinformatics, Faculty of Engineering, University of Lagos, Nigeria. \\ ${ }^{2}$ Global Geodetique Solution Limited, Unilag Consult, University of Lagos, Nigeria.
}

ABSTRACT: A set of Continuously Operating Reference Stations (CORS) distributed all over Nigeria constitutes the Nigerian GNSS Reference Network referred to as NIGNET. Global Navigation Satellite System (GNSS) is a system that uses satellites for autonomous position determination, and is a critical component of the modern-day geodetic infrastructure and services. Using CORS provide geodetic controls of comparable accuracy and a better alternative to the classical geodetic network. As the NIGNET infrastructure is utilised for different geodetic applications, it has become necessary to evaluate the suitability of the network data for the definition of a geodetic reference frame (GRF). This study utilised the technique of Precise Point Positioning (PPP) in position estimation, and time series analysis for temporal monitoring of the network. The sufficiency and adequacy of the NIGNET data archive was also evaluated against that of an International GNSS Service (IGS) Station. The temporal stability of the station coordinates measured in terms of standard deviations varied between $10 \mathrm{~mm}$ and $22 \mathrm{~mm}$. This analysis suggests a relative stability required for Tiers 1 and 2 CORS in line with the IGS standards. Based on this reported stability, it is concluded that NIGNET is fit for purpose in defining the Nigerian Geodetic Reference Frame. However, despite the good data quality observed, the adequacy of the network has been compromised by infrastructural failures and lack of continuity in data transmission. Accordingly, it is recommended that both practical and policy measures required to ensure the realisation of the goal of the network should be implemented.

KEYWORDS: Geodetic reference frame, NIGNET, CORS, precise point positioning, temporal stability and adequacy.

[Received January 29, 2019, Revised July 3, 2019, Accepted September 22, 2019]

Print ISSN: 0189-9546 | Online ISSN: 2437-2110

\section{INTRODUCTION}

The Nigerian Geodetic Reference Framework (GRF) has been plagued by many problems such as improper datum definition, hybrid observations and faulty adjustment methods. These problems started from the early establishment of the network and are well documented in several publications, including Daniels (1973), Omoigui (1973), Ogwude (1974), Field (1977) and Omoigui and Fadahunsi (1980). The Nigerian Triangulation System is not homogeneous, nor the resulting coordinates consistent due to varying degrees of precision of observations and many instrument types used over many years (Fajemirokun, 2006). In more advanced climes, there has been a transition from passive control networks determined using classical surveying methods to modern networks established by Global Navigational Satellite System (GNSS) techniques.

Today, the availability of Continuously Operating Reference Station (CORS) has revolutionised the realisation of geodetic datum with a shift from the conventional ground survey methods (LPI, 2012). CORS is a network of stations using GNSS operating continuously from permanent and stable locations for accurate positioning (Fajemirokun, 2009; Schwieger et al, 2009). GNSS (particularly the Global Positioning System - GPS) has become a critical component

*Corresponding author: cokolie@unilag.edu.ng of the modern-day geodetic infrastructure and services. Currently, anyone with a GNSS receiver can access the signals transmitted by a GNSS system for the provision of accurate position, velocity and time information (Andrei et al, 2010). CORS are categorised into different classes according to purpose and the spacing between stations. For example, Burns and Sarib (2010) and ICSM (2014) classified CORS into Tiers $1-3$ while LPI (2012) classified CORS into Tiers $1-5$. CORS can give an instant position to an accuracy of $\pm 20 \mathrm{~mm}$ required by many industries (UNSW, 2017). Also, multiple reference stations can be used for position correction to effectively eliminate accuracy degradation with increasing range between reference stations and rover (Hale et al, 2006; Iyiola et al, 2013). Primarily, CORS are used to collect data to monitor geodynamic movement as applied in geosciences, and are also used for spatially related activities that include urban and regional planning, land administration, transport, asset management as well as environmental monitoring (Snay and Soler, 2008; ICSM, 2014).

Using CORS, position and velocity associated with a given site represent the crustal position and velocity of the site, and not just of the antenna (NOAA, 2013). This concept is very useful for geodynamic studies. For example, a natural phenomenon due to geophysical processes such as earthquakes

doi: http://dx.doi.org/10.4314/njtd.v17i1.1 
could displace a CORS antenna to produce significant station displacements that should be computed and corrected (Soler et al, 2003). Recently, on the 11th and 12th September 2016, some communities (Qei, Jaba, Kwoi, Nok, Sanbah and Chori) in Kaduna State Nigeria, were affected by earth tremors (Nwilo et al, 2016). Therefore, critical to the users of the data is the need to account for any displacement arising from the shift in position of the CORS. For example, the United States National Geodetic Survey (NGS) monitors the quality of the computed coordinates and compiles the plots of the variation of the CORS as a by-product through daily solutions by exploiting the most advanced GPS methodologies and software (Soler et al, 2003).

The Office of the Surveyor General of the Federation (OSGOF) started the Nigerian GNSS Network (NIGNET) in 2008. This network (NIGNET) forms an integral part of the national geodetic infrastructure and is currently composed of sixteen CORS uniformly distributed across the country (Nwilo et al, 2016). The establishment of NIGNET in line with the International GNSS Service (IGS) standards contributes to the objectives of the African Geodetic Reference Frame (AFREF). Ezeigbo (2007) noted that AFREF is homogeneous and consistent with the International Terrestrial Reference Frame (ITRF), and it provides a means of unifying geodetic networks in the continent. Accordingly, NIGNET is linked to the ITRF. ITRF is the most accurate reference frame internationally defined by International Earth Rotation and Reference Service (IERS) using a combination of space-based geodetic techniques such as GPS and Very Long Baseline Interferometry (VLBI) (Schwieger et al, 2009). The linking of the NIGNET to the ITRF2008 was through continuous and simultaneous acquisition of GPS data from nine IGS stations (OSGOF, 2012). The IGS stations served as the fiducial points in the data processing. Therefore, NIGNET provides a consistent national coordinate system that supports mapping, charting, navigation, boundary determination, property delineation, infrastructure development, resource evaluation surveys, and other scientific applications (Fajemirokun, 2009).

In this study, the offline version of the GNSS Analysis and Positioning Software (GAPS) developed at the University of New Brunswick, Canada was used for position determination based on the Precise Point Positioning (PPP) technique. To monitor and detect temporal variations and the quality of the three-dimensional coordinates, a time-series analysis of the NIGNET CORS data covering 2011 to 2014 was performed. using $R . R$ is a free software environment for statistical computing and graphics that can be compiled and run on Windows and MacOS (R Core Team, 2017). The evaluation of the accuracy and adequacy of the CORS network for the definition and realisation of the Nigerian Geodetic Reference Frame follows the IGS and international standards.

\section{THEORETICAL FRAMEWORK}

\section{A. The Basic Principle of GNSS}

The basic principle behind a satellite navigation system is the creation of a trilateration network from any point on the earth's surface to the satellites in view (Lechner and Baumann, 2000). At least three satellites must be available to determine the three-dimensional position of a receiver. More satellites are needed to eliminate the time difference between the satellites' atomic clocks and the receivers' quartz clocks, and for integrity checks (quality control etc.) (Lechner and Baumann, 2000). Given the exact positions of the satellites $P_{i}\left(x_{i}, y_{i}, z_{i}\right), i=$ 1,2,3,4 (Fig. 1), the distances (ranges) to the satellites can be determined by the following system of equations (TAMU, 2017):

$$
\begin{aligned}
& d_{1}=\sqrt{\left(x-x_{1}\right)^{2}+\left(y-y_{1}\right)^{2}+\left(z-z_{1}\right)^{2}}+c t_{B} \\
& d_{2}=\sqrt{\left(x-x_{2}\right)^{2}+\left(y-y_{2}\right)^{2}+\left(z-z_{2}\right)^{2}}+c t_{B} \\
& d_{3}=\sqrt{\left(x-x_{3}\right)^{2}+\left(y-y_{3}\right)^{2}+\left(z-z_{3}\right)^{2}}+c t_{B} \\
& d_{4}=\sqrt{\left(x-x_{4}\right)^{2}+\left(y-y_{4}\right)^{2}+\left(z-z_{4}\right)^{2}}+c t_{B}
\end{aligned}
$$

where:

$c=$ speed of light

$t_{B}=$ receiver clock offset time.

The measured travel time of the radio waves and the distances to the satellites are used to compute the position of the receiver, $R(x, y, z)$. Traditionally, GNSS data acquired in static mode using dual-frequency receivers is subjected to post-processing on a desktop using corrections from a geodetic control. Recently, a standalone positioning technique known as Precise Point Positioning (PPP) in which the user requires no connection to geodetic controls (or base stations) has been gaining ground. This concept is considered in the next section.

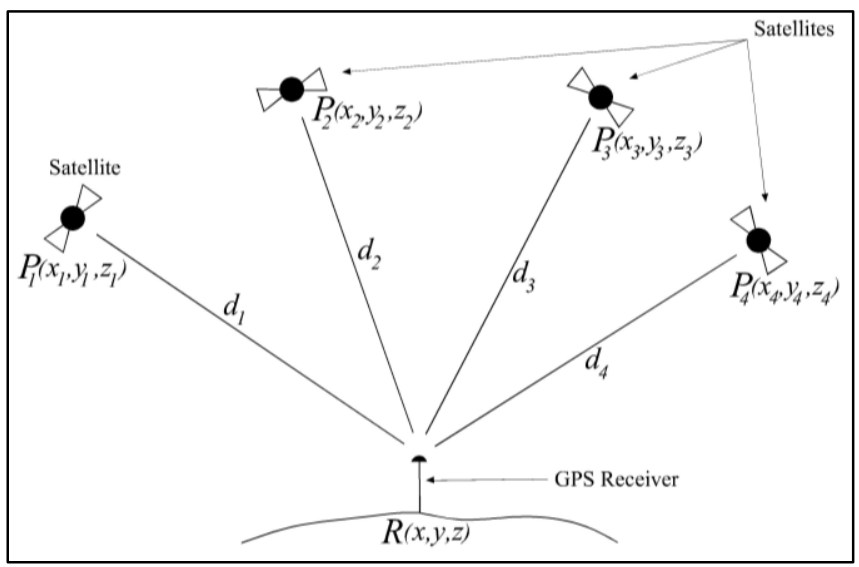

Fig. 1: GNSS technique for position determination (after Ayodele et al, 2017).

\section{B. The Principle of Precise Point Positioning (PPP)}

Precise Point Positioning (PPP) is a technique of positioning that uses a single GNSS receiver that requires external information from analysis of the global GNSS permanent network (Tomasz, 2015). The concept of PPP was first introduced in the 1970s. However, following GrejnerBrzezinska (2009), the basic mathematical model underlying the dual frequency PPP is defined by the desired ionosphere 
free combination of code pseudo-ranges in Eq. (5) and carrier phases in Eq. (6):

$$
R_{1,2}=R_{1}-\frac{f_{2}^{2}}{f_{1}^{2}} R_{2}
$$

$\phi_{1,2}=\alpha_{1} \phi_{1}+\alpha_{2} \phi_{2}=\rho+T+\alpha_{1} \lambda_{1} N_{1}+\alpha_{2} \lambda_{2} N_{2}+$

$\alpha_{1} \varepsilon_{1}+\alpha_{2} \varepsilon_{2}$

where:

$\alpha_{1}=\frac{f_{1}^{2}}{f_{1}^{2}-f_{2}^{2}} ; \alpha_{2}=-\frac{f_{2}^{2}}{f_{1}^{2}-f_{2}^{2}}$

$\phi_{1,2}=$ phase ranges; $f_{l, 2}=$ carrier frequencies; $R_{l, 2}=$ pseudo-ranges; $T=$ tropospheric refraction term; $N_{l, 2}=$ ambiguities associated with the frequencies, $\lambda_{1,2}=$ wavelengths; $\varepsilon_{1,2}=$ measurement noise for carrier phases; $\rho=$ geometric distance between satellite and receiver.

PPP uses undifferenced dual-frequency pseudo-range and carrier phase observations along with precise GPS satellite orbit and clock products (Cai, 2009). The PPP method for a static application was first introduced by Zumberge et al. (1997) but in recent years it has been modified to accommodate kinematic applications as well (e.g. Kouba and Héroux, 2001; Ovstedal et al, 2006). PPP has been shown to give centimetrelevel positioning accuracy in static mode and sub-decimetre level accuracy in kinematic mode (e.g. Kouba and Héroux, 2001; Gao et al, 2003; Gao and Chen, 2004). Another significant advantage of PPP is the availability of online automatic services for position estimation (Dawidowicz and Krzan, 2014). Some of the available PPP services worldwide include Geoscience Australia's Online GPS Data Processing Service (AUSPOS), the Online Positioning User Service (OPUS) by the US National Geodetic Survey, and the GPS Analysis and Positioning Software (GAPS) by the University of New Brunswick, Canada. However, using PPP for position determination has some limitations since it involves the use of only one GNSS receiver. For example, no difference between two receivers can be built to eliminate satellite specific errors such as clock and orbital errors (Huber et al, 2010). However, in the near future, PPP might substitute not only postprocessing of network solutions but also real-time differential GPS or even Real-Time Kinematic (RTK) in many applications (Huber et al, 2010).

\section{1.) Precise Point Positioning using GAPS}

The GPS Analysis and Positioning Software (GAPS) is a versatile PPP application that provides state-of-the-art conventional results in either static or kinematic mode (Leandro et al, 2010). GAPS uses the least-squares technique in position estimation and the application is available online through the UNB Geodesy and Geomatics Engineering Research and Learning Resources web page (http://gge.unb.ca/). For batch processing, an offline version at
UNB provides more capabilities. When compared to other PPP services, GAPS offers some important and unique advantages. For example, GAPS can accurately retrieve the mean multipath effect of a satellite arc, in contrast to other inaccurate multipath retrieval techniques. GAPS produces values of the satellite code biases, based on a positioning observation model, as opposed to satellite clock estimation observation model which is usually the case when bias values are provided to users (Leandro et al, 2007). Regarding satellite clock error estimates, GAPS was enhanced to provide estimates of satellite clock offsets. For more information, a detailed description of the software is presented in Leandro et al. (2007) and Leandro et al. (2010). Table 1 defines the parameters used in the data processing such as carrier-phase standard deviation of $15 \mathrm{~mm}$.

Table 1: Parameters used in the processing of the NIGNET RINEX files.

\begin{tabular}{|c|c|}
\hline Item & Models \\
\hline Observations & $\begin{array}{l}\text { GPS Undifferenced, ionosphere-free } \\
\text { linear combination of L1 and L2 } \\
\text { carrier-phase \& pseudo range }\end{array}$ \\
\hline Orbit products & IGS final product \\
\hline Clock products & IGS final product \\
\hline Clock Interpolation & Interpolate static clock \\
\hline Processing mode & Static \\
\hline Elevation cut-off & $10^{\circ}$ \\
\hline Orbit Type & Standard \\
\hline $\begin{array}{l}\text { Carrier-phase standard } \\
\text { deviation }\end{array}$ & $0.015 \mathrm{~m}$ \\
\hline $\begin{array}{l}\text { Pseudo range standard } \\
\text { deviation }\end{array}$ & $2 \mathrm{~m}$ \\
\hline $\begin{array}{l}\text { Positional solution } \\
\text { convergence condition }\end{array}$ & 1 \\
\hline $\begin{array}{l}\text { Maximum number of } \\
\text { iterations }\end{array}$ & 5 \\
\hline $\begin{array}{l}\text { Maximum allowable GDOP } \\
\text { value }\end{array}$ & 20 \\
\hline $\begin{array}{l}\text { A Priori Neutral Atmospheric } \\
\text { delay }\end{array}$ & VMF1 \\
\hline Mapping function & VMF \\
\hline $\begin{array}{l}\text { Initial NAD standard } \\
\text { deviation }\end{array}$ & $0.1 \mathrm{~m}$ \\
\hline NAD random walk & $5 \mathrm{~mm} / \mathrm{h}$ \\
\hline Phase-windup effect & Applied \\
\hline Ambiguities & Estimated as real numbers \\
\hline Station displacement & $\begin{array}{l}\text { Solid Earth tide and Ocean tide } \\
\text { loading (IERS Convention 2010) }\end{array}$ \\
\hline Satellite antenna & $\begin{array}{l}\text { Phase Centre Offset and Phase } \\
\text { Centre Variation corrected }\end{array}$ \\
\hline Receiver antenna & $\begin{array}{l}\text { Phase Centre Offset and Phase } \\
\text { Centre Variation corrected }\end{array}$ \\
\hline Reference Frame & ITRF 08 \\
\hline
\end{tabular}

\section{MATERIALS AND METHODS}

Fig. 2 presents the flowchart of the data acquisition and analysis procedure for the CORS data from NIGNET and IGS. Essentially, the procedure shows the main stages involved starting from the data acquisition stage to results display and analysis. 


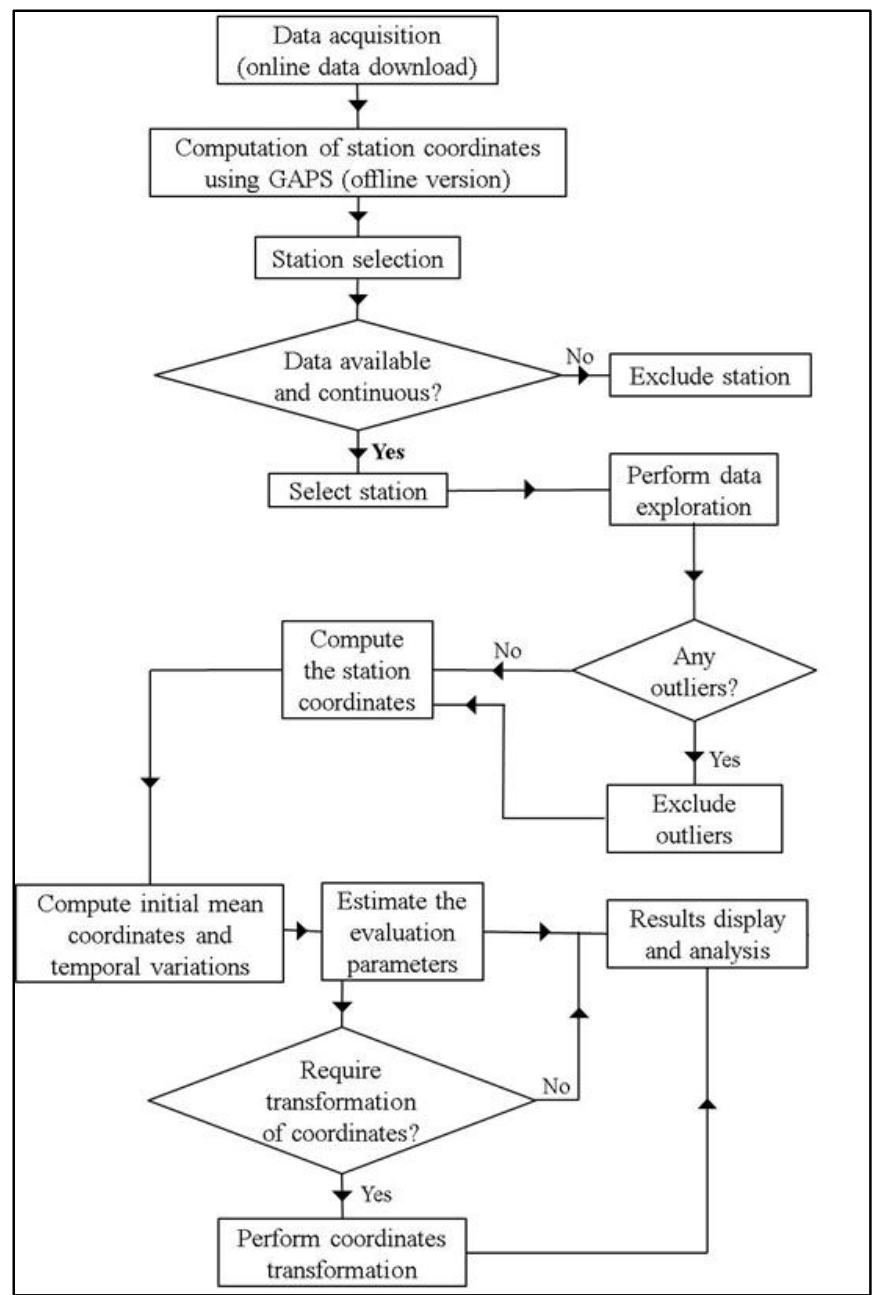

Fig. 2: Flowchart of the research methodology (after Ayodele et al, 2017).

\section{A. Data Acquisition}

The area of study covers the entire country where CORS are established. Fig. 3 shows the spatial distribution of the NIGNET CORS network and the selected stations for this study colour-coded in blue. Fig. 4 presents some of the components of a typical COR station in NIGNET that include a housing unit and an installed choke-ring antenna. From the NIGNET website, the RTKGET application program of RTKLIB (shown in Fig. 5) was customised and used to download the RINEX files/data of the respective stations. RTKGET is a software utility of the open source RTKLIB program package used for downloading observation data from CORS networks. RTKLIB is used for standard and precise positioning with GNSS.

\section{B. Data Processing}

\section{1.) Computation of station coordinates using GAPS}

Following the data acquisition stage, the first stage of the data processing utilised the GAPS offline function. The downloaded GNSS RINEX files were moved to the appropriate folder in the GAPS engine to enable the reading and processing of the data. To do this, a custom code written in-house was used to call the GAPS offline function to read the RINEX files from the folder they were placed. The processing generated several files and plots for each epoch (day of observation). For example, Fig. 6 shows the pseudo random noise (PRN) codes of the GPS satellites used in the solution of station CLBR on the 1st of January, 2016. The geocentric coordinates of the stations were also computed and extracted from the generated files while effectively handling the days that had no data.

\section{2.) Station selection}

One of the IGS requirements is the need to have long time series of continual stable measurements with as few disruptions and configuration changes as possible (IGS, 2017). Therefore, the criteria for station selection was predicated on the availability of a continuous, sufficient and consistent series of data from the respective stations to ensure reliability. ICSM (2014) defined data reliability as a function of three parameters - stability of the antenna reference point, signal tracking and data recording, and data transmission. For Tiers 1 and 2, less than $8 \mathrm{~min} /$ day and $9 \mathrm{hr} / \mathrm{year}$ of data outage is recommended, while for Tier 3 CORS, data outage should be less than 15 $\mathrm{min} / \mathrm{day}$ and $44 \mathrm{hr} / \mathrm{year}$. Similarly, the latency of the data transmission for archiving should be less than 5 mins for hourly data and less than 15 mins for daily data following the last observation (ICSM, 2014).

However, the criteria stated above were relaxed in the selection process to ensure some stations were retained for analysis. Nevertheless, any station or year (from 2011 to 2016) with excessively large data gaps were eliminated from the analysis as observed in the year 2014 at station ULAG. Overall, seven stations with length of data extending to 2014 were selected for temporal monitoring analysis. Table 2 presents the summary of the selected stations showing the geodetic coordinates and years of observations considered.

\section{3.) Data exploration}

The initial exploration of the data considered the sampling conformity - recommended at $1,5,15$ or 30-second sampling interval (NOAA, 2013). Following the sampling conformity (30-second interval), the next step of the exploration considered outliers in the data. This is necessary to avoid any undue influence of the outlying values on the analysis. To do this, the Tukey (Box-and-Whisker) method of outlier detection was used to explore the distribution of the daily coordinates computed using GAPS. The Tukey's method defines outliers as values greater than $Q 3+1.5 * I Q R$ and values less than $Q 1-1.5 * I Q R$, where $Q 1, Q 3$, and $I Q R$ are the lower quartile, upper quartile, and inter-quartile range respectively (Crawley, 2005). For example, Fig. 7 presents the boxplots of the computed coordinate differences from two stations (OSGF and ULAG) using the Tukey filtering method. 


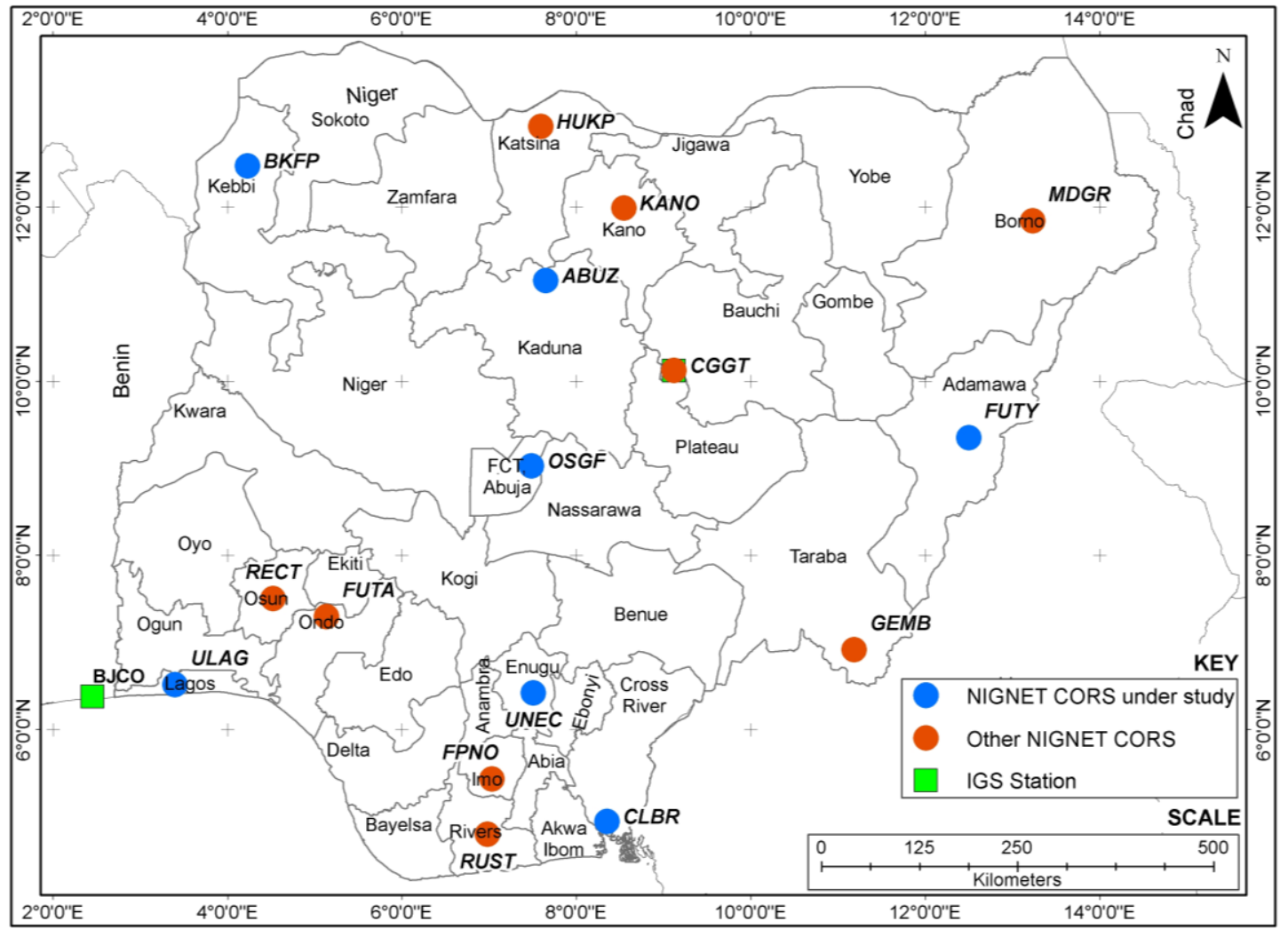

Fig. 3: Map of Nigeria showing the distribution of the COR stations.

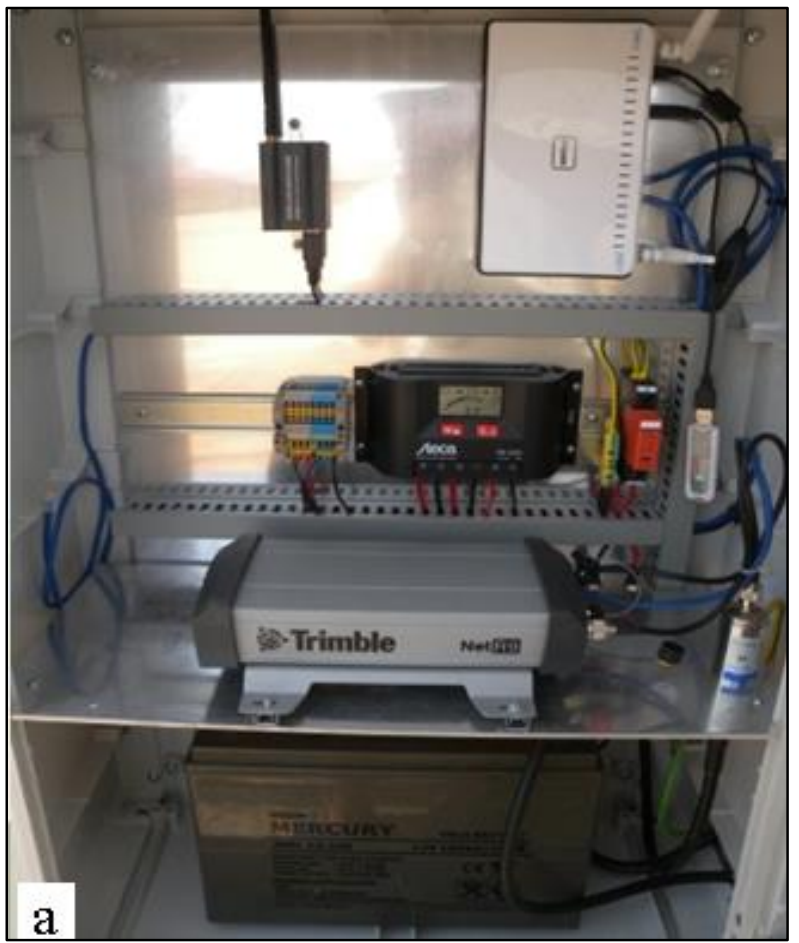

Fig. 4: (a) Receiver, solar power and internet accessories. (Image courtesy of OSGOF).

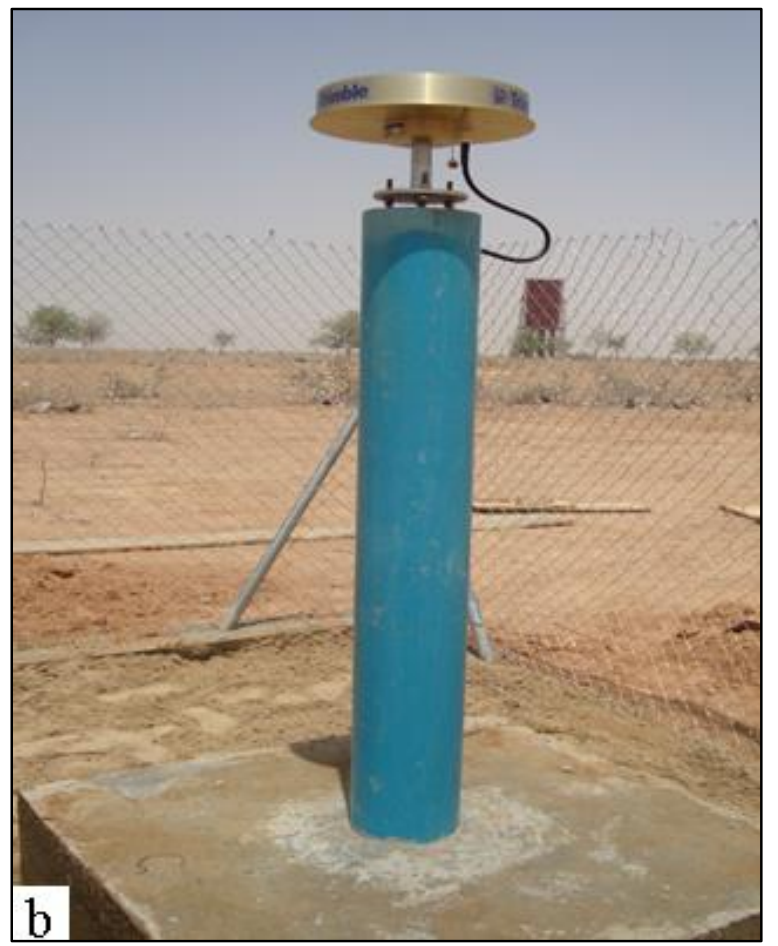

Fig. 4: (b) Choke-Ring Antenna at a typical NIGNET station. (Image courtesy of OSGOF). 


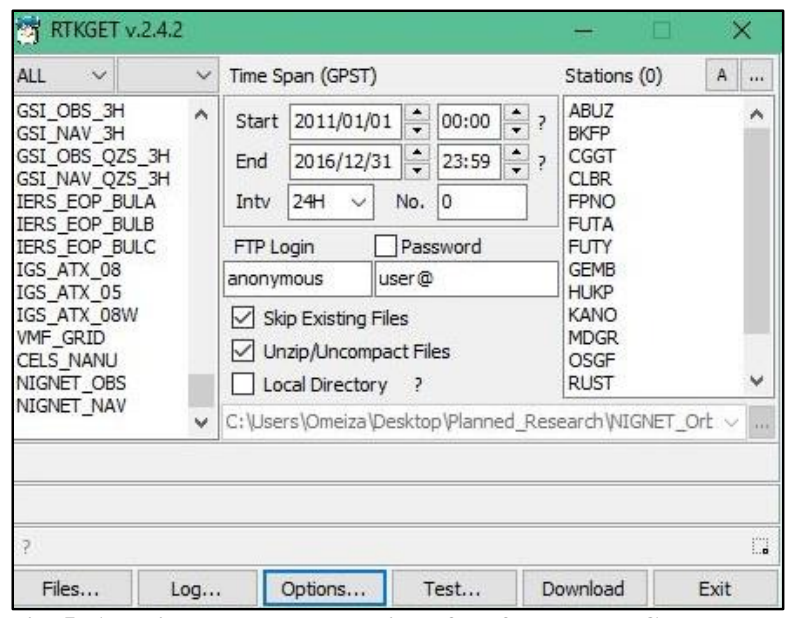

Fig. 5: A typical data download interface from the NIGNET site using RTKGET.

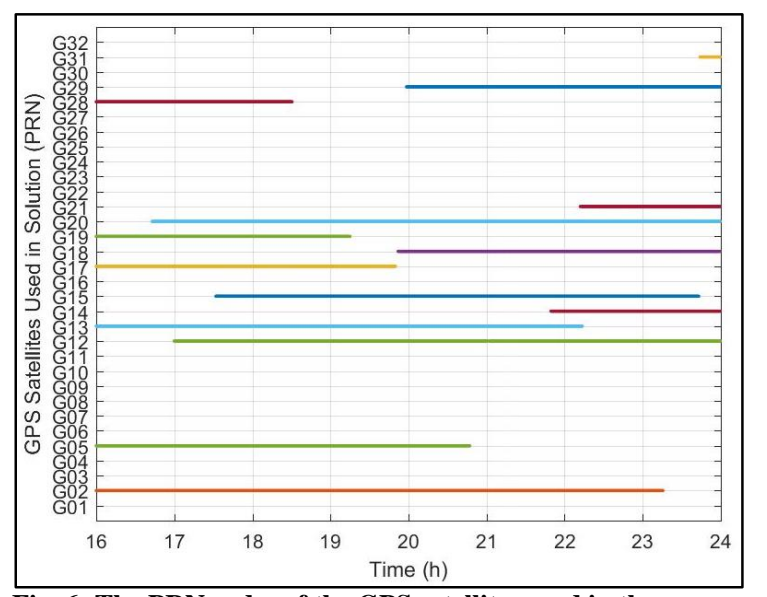

Fig. 6: The PRN codes of the GPS satellites used in the solution of station CLBR on 1st January 2016.

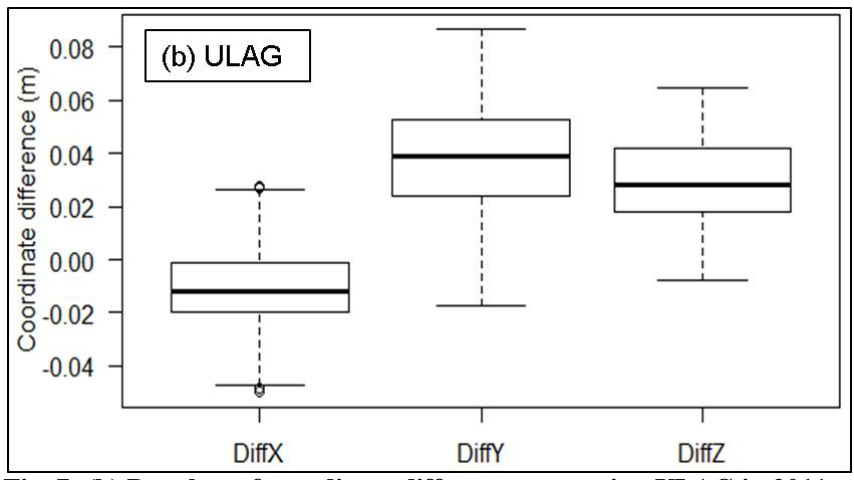

Fig. 7: (b) Boxplots of coordinate differences at station ULAG in 2011.

\section{4.) Computation of the initial station coordinates and temporal variations}

After the stepwise elimination of the outliers, the final set of the daily coordinates for the first epochs were averaged to derive the initial coordinates for each station. Janssen (2009) recommended the use of coordinates determined during installation, after six months and eighteen months and every two years thereafter as reference marks for Tiers 1 and 2 CORS. The computed initial coordinates compared favourably well with the initial coordinates obtained from OSGOF and were adopted as the reference values. Further evaluations of the accuracy of each station's position that includes the estimation of assessment parameters were based on the set of the initial coordinates. For all the stations excluding CLBR, which started in 2012, the starting epoch adopted was 2011 as shown in Table 2.

\section{5.) Parameter estimation}

To understand the temporal stability of the stations as well as how well they are fit for purpose according to the IGS

Table 2: The selected stations, attributes and years of observations.

\begin{tabular}{|c|c|c|c|c|c|c|c|c|}
\hline \multirow{2}{*}{$\begin{array}{l}\text { Station } \\
\text { Code }\end{array}$} & \multirow{2}{*}{$\begin{array}{l}\text { Latitude } \\
\text { (degree) }\end{array}$} & \multirow{2}{*}{$\begin{array}{l}\text { Longitude } \\
\text { (degree) }\end{array}$} & \multirow{2}{*}{$\begin{array}{l}\text { Ellipsoidal height } \\
\text { (m) }\end{array}$} & \multirow[t]{2}{*}{ Location } & \multicolumn{4}{|c|}{ Years of Observations } \\
\hline & & & & & 2011 & 2012 & 2013 & 2014 \\
\hline ABUZ & 11.152 & 7.649 & 697.082 & Zaria & $\sqrt{ }$ & $\sqrt{ }$ & $\sqrt{ }$ & $\sqrt{ }$ \\
\hline BKFP & 12.469 & 4.229 & 242.031 & Birnin Kebbi & $\sqrt{ }$ & $\sqrt{ }$ & $\sqrt{ }$ & $\sqrt{ }$ \\
\hline CLBR & 4.950 & 8.352 & 49.179 & Calabar & $\mathrm{x}$ & $\sqrt{ }$ & $\sqrt{ }$ & $\sqrt{ }$ \\
\hline FUTY & 9.350 & 12.498 & 239.413 & Yola & $\sqrt{ }$ & $\sqrt{ }$ & $\sqrt{ }$ & $\sqrt{ }$ \\
\hline OSGF & 9.028 & 7.486 & 524.657 & Abuja & $\sqrt{ }$ & $\sqrt{ }$ & $\sqrt{ }$ & $\sqrt{ }$ \\
\hline ULAG & 6.517 & 3.398 & 36.572 & Lagos & $\sqrt{ }$ & $\sqrt{ }$ & $\sqrt{ }$ & $\mathrm{x}$ \\
\hline UNEC & 6.425 & 7.505 & 246.404 & Enugu & $\sqrt{ }$ & $\sqrt{ }$ & $\sqrt{ }$ & $\sqrt{ }$ \\
\hline
\end{tabular}

NB: $\sqrt{ }$ - selected, $\mathrm{x}$ - not selected

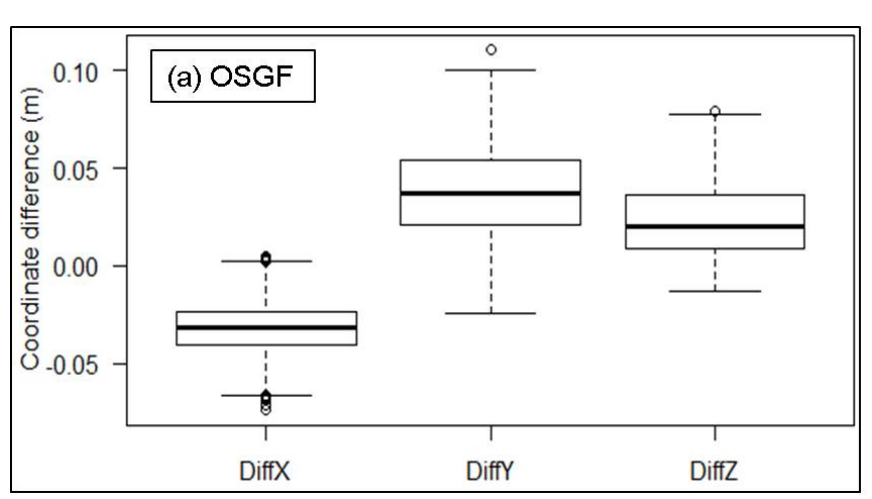

Fig. 7: (a) Boxplots of coordinate differences at station OSGF in 2011. guidelines and CORS classifications, the following parameters were computed - mean coordinate differences and standard deviation (SD) across the stations. Different accuracy standards have been achieved across the globe depending on the purpose of establishment. However, the IGS (2015) site guidelines stated that the COR station is expected to have highquality data (phase convergence in AC/PPP) analysis less than $15 \mathrm{~mm}$, and zero horizontal eccentricity of antenna reference point relative to East/North. ICSM (2014) also recommended a survey uncertainty of better than $20 \mathrm{~mm}$. These recommendations formed the basis for the data quality assessment. 


\section{RESULTS AND DISCUSSION}

A. Assessment of the Initial and Yearly Coordinates

This section presents the results of the assessment conducted on the initial and yearly coordinates of the station for a preliminary understanding of the network. Table 3 presents the computed mean and standard deviations (SD) of the initial station coordinates and the number of data points used $(\mathrm{N})$. In the $\mathrm{x}$-direction, ABUZ has the lowest SD (10.2 $\mathrm{mm})$ while CLBR has the highest SD $(20.7 \mathrm{~mm})$. In the $\mathrm{y}$ direction, OSGF has the lowest SD $(7.3 \mathrm{~mm})$ while CLBR has the highest SD (12.2 mm). Similarly, OSGF and CLBR have the lowest and highest SDs in the z-direction (OSGF $-4.8 \mathrm{~mm}$, CLBR - $9.6 \mathrm{~mm}$ ). From the analysis, the performance of direction with a minimum standard deviation of $4.4 \mathrm{~mm}$ at OSGF in 2014 and maximum standard deviation of $11.7 \mathrm{~mm}$ at BKFP in 2013. The $x$ and $y$-directions are favourably comparable in precision with minimum standard deviations of $11.2 \mathrm{~mm}$ and $9.0 \mathrm{~mm}$ respectively occurring at OSGF in 2014 and ABUZ in 2012. On the other hand, the maximum standard deviations for $\mathrm{x}$ and $\mathrm{y}$-directions $(16.7 \mathrm{~mm}$ and $18.8 \mathrm{~mm}$ respectively) occurred at UNEC in 2012 and FUTY in 2013. Clearly, the randomness in the results over the stations and years of observations showed the absence of systematic errors, which is an interesting observation. In general, the results obtained showed an acceptable level in the data quality and accuracy given a $20 \mathrm{~mm}$ benchmark as defined by UNSW (2017). The next step presents the plots of the temporal

Table 3: The mean and standard deviation of the initial coordinates computed over year 2011 for the selected locations.

\begin{tabular}{|c|c|c|c|c|c|c|c|}
\hline Station Code & $\bar{X}_{i}(\mathbf{m})$ & $\bar{Y}_{i}(\mathbf{m})$ & $\bar{Z}_{i}(\mathbf{m})$ & $S D_{X_{i}}(\mathrm{~mm})$ & $S D_{Y_{i}}(\mathrm{~mm})$ & $S D_{Z_{i}}(\mathrm{~mm})$ & $\mathbf{N}$ \\
\hline ABUZ & 6203493.8186 & 833088.7134 & 1225614.6444 & 10.2 & 8.8 & 4.9 & 349 \\
\hline BKFP & 6211960.3439 & 459365.4923 & 1368115.0576 & 11.2 & 9.3 & 5.1 & 348 \\
\hline CLBR & 6287174.1988 & 922979.4810 & 546713.7924 & 20.7 & 12.2 & 9.6 & 216 \\
\hline FUTY & 6145058.4939 & 1362078.8908 & 1029389.9252 & 11.1 & 10.1 & 5.8 & 334 \\
\hline OSGF & 6246471.2537 & 820848.7511 & 994267.9420 & 12.3 & 7.3 & 4.8 & 262 \\
\hline ULAG & 6326097.2967 & 375576.1197 & 719131.7003 & 14.2 & 11.3 & 6.7 & 286 \\
\hline UNEC & 6284298.3053 & 827900.5266 & 708988.5981 & 14.8 & 9.7 & 5.6 & 338 \\
\hline
\end{tabular}

CLBR may not be unconnected with the coastal location and the number of data points used (216) being the lowest sample. The maximum variability occurred in the $\mathrm{x}$-direction and the minimum in the z-direction. Overall, the results indicate a relative stability and a level of acceptance of the computed initial coordinates to be used for the validation of the yearly coordinates. Similarly, Table 4 presents the summary of the coordinates of the stations on yearly basis from 2012 to 2014 (i.e. excluding the starting epochs). Consistent with the 2011 results in Table 3, the highest precision was observed in the z- variations in terms of position.

\section{B. Understanding Temporal Changes}

Variability is a measure of dispersion or spread in a data. High or low variability according to statistical test is a useful measure of the data quality. Accordingly, understanding temporal changes across NIGNET is fundamental to its suitability in defining a geodetic reference frame. Following the statistical analysis conducted, Fig. 8 presents the standard

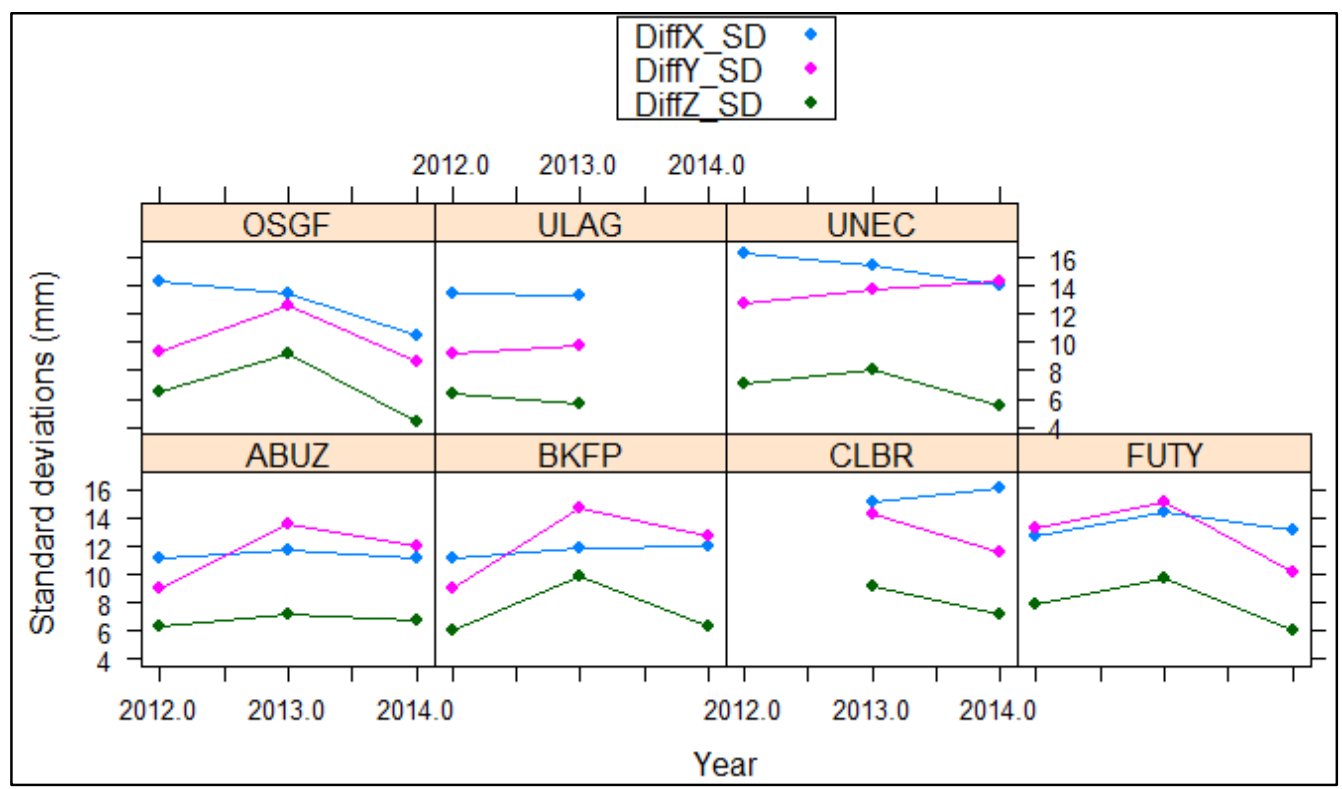

Fig. 8: Standard deviations over the COR stations on yearly basis in 3-dimensions. 
deviations plot across the stations in a 3-dimensional space in order to rapidly compare the three dimensions.

From Fig. 8, the results showed a general rise from 2012 to 2013 and a fall in 2014 in the 3-dimensions that reflects more stability in the stations than the previous year. Overall, the results showed a maximum variability in the X-direction for all the stations - except at stations ABUZ, BKFP, and FUTY, which are all situated in the northern part of the country. The suitability in defining a geodetic reference frame. Table 5 presents the summary of the stations coordinates showing the mean differences in coordinates, the standard deviations and the number of samples. Overall, ABUZ and BKFP have the highest samples of 1005 and 1007 respectively, followed by FUTY (913). Investigation conducted showed that stations that are located in the south have antenna problems due to damage from thunderstorm as a result of heavier rainfall compared to the stations located in the north. However, the challenge is

Table 4: The mean and standard deviation of the yearly station coordinates.

\begin{tabular}{|c|c|c|c|c|c|c|c|c|}
\hline Station Code & Year & $\bar{X}(\mathbf{m})$ & $\bar{Y}(\mathbf{m})$ & $\bar{Z}(\mathbf{m})$ & $S D_{X}(\mathrm{~mm})$ & $S D_{Y}(\mathrm{~mm})$ & $S D_{Z}(\mathrm{~mm})$ & $\mathbf{N}$ \\
\hline ABUZ & 2012 & 6203493.8071 & 833088.7341 & 1225614.6629 & 11.9 & 9.0 & 6.4 & 358 \\
\hline ABUZ & 2013 & 6203493.8026 & 833088.7568 & 1225614.6827 & 13.0 & 14.0 & 7.6 & 331 \\
\hline ABUZ & 2014 & 6203493.7921 & 833088.7751 & 1225614.7025 & 11.9 & 13.2 & 7.6 & 335 \\
\hline BKFP & 2012 & 6211960.3314 & 459365.5133 & 1368115.0760 & 12.0 & 9.1 & 6.3 & 357 \\
\hline BKFP & 2013 & 6211960.3287 & 459365.5389 & 1368115.0960 & 14.2 & 15.1 & 11.7 & 321 \\
\hline BKFP & 2014 & 6211960.3187 & 459365.5583 & 1368115.1145 & 12.4 & 15.6 & 6.3 & 350 \\
\hline CLBR & 2013 & 6287174.2007 & 922979.5053 & 546713.8112 & 14.5 & 16.8 & 9.0 & 276 \\
\hline CLBR & 2014 & 6287174.1901 & 922979.5247 & 546713.8317 & 15.1 & 11.5 & 7.1 & 336 \\
\hline FUTY & 2012 & 6145058.4821 & 1362078.9132 & 1029389.9439 & 14.4 & 14.7 & 8.1 & 320 \\
\hline FUTY & 2013 & 6145058.4733 & 1362078.9362 & 1029389.9636 & 15.2 & 18.8 & 9.9 & 343 \\
\hline FUTY & 2014 & 6145058.4611 & 1362078.9569 & 1029389.9833 & 14.7 & 11.9 & 6.3 & 273 \\
\hline OSGF & 2012 & 6246471.2435 & 820848.7694 & 994267.9592 & 14.8 & 10.7 & 6.6 & 354 \\
\hline OSGF & 2013 & 6246471.2422 & 820848.7913 & 994267.9803 & 14.8 & 19.0 & 9.7 & 313 \\
\hline OSGF & 2014 & 6246471.2457 & 820848.8039 & 994267.9977 & 11.2 & 9.2 & 4.4 & 90 \\
\hline ULAG & 2012 & 6326097.2861 & 375576.1434 & 719131.7189 & 13.5 & 9.7 & 6.5 & 350 \\
\hline ULAG & 2013 & 6326097.2882 & 375576.1635 & 719131.7356 & 13.8 & 9.9 & 5.8 & 264 \\
\hline UNEC & 2012 & 6284298.2923 & 827900.5481 & 708988.6164 & 16.7 & 15.0 & 7.2 & 353 \\
\hline UNEC & 2013 & 6284298.2928 & 827900.5749 & 708988.6382 & 15.4 & 16.4 & 8.9 & 342 \\
\hline UNEC & 2014 & 6284298.2846 & 827900.5902 & 708988.6551 & 13.9 & 17.2 & 6.3 & 215 \\
\hline
\end{tabular}

higher variability in the south may be explained by the fact that the atmosphere in the southern part of the country is more humid (more water vapour content) than the northern part of the country (Mayaki et al, 2018). A more humid atmosphere can degrade positioning accuracy due to increased refraction of radio signals in space (Pace et al, 2015). However, a holistic assessment of the other stations in the north will be required to arrive at a generalisable conclusion. In the further analysis, the $\mathrm{z}$-component is consistently the least variable across all the stations. The temporal variation $(4 \mathrm{~mm}$ and $17 \mathrm{~mm}$ standard deviations) is within the specified standards of $20 \mathrm{~mm}$ given by UNSW (2017). For ULAG, the variation presents a slightly downward trend between 2012 and 2013 in the z-direction as opposed to the upward trend observed over the other stations.

\section{Accuracy Assessment}

This section considers the accuracy assessment in order to understand the stability of the network as a measure of its currently being addressed through the procurement of receivers with thunder arrester to ensure longevity and continuity in data collection. Overall, while the mean differences vary between $-4 \mathrm{~mm}$ to $44 \mathrm{~mm}$, the standard deviations vary between $10 \mathrm{~mm}$ to $22 \mathrm{~mm}$ which can be said to be within the required limit despite the $22 \mathrm{~mm}$ observed in the y-direction at BKFP. For the station summary, the $\mathrm{x}$ component is considered the most accurate as evident from Table 5. The table shows that the $\mathrm{x}$-direction has a maximum standard deviation of $16.6 \mathrm{~mm}$ compared to $22.3 \mathrm{~mm}$ in the $\mathrm{y}$ direction and $17.7 \mathrm{~mm}$ in the z-direction. However, at stations CLBR and ULAG, the z-direction is better than the $\mathrm{x}$-direction, while the $y$-direction is consistently the least accurate compared to the other directions except at station CLBR where it marginally outperformed the $\mathrm{X}$-directional coordinate. This observation at station CLBR is attributed to the few data points used in the analysis as against its geographical location given

Table 5: The computed mean coordinates, difference in coordinates over time, standard deviations, and the number of samples used.

\begin{tabular}{|c|c|c|c|c|c|c|c|c|c|c|}
\hline $\begin{array}{c}\text { Station } \\
\text { Code }\end{array}$ & $\bar{X}_{o}(\mathbf{m})$ & $\overline{\boldsymbol{Y}}_{o}(\mathbf{m})$ & $\bar{Z}_{o}(\mathbf{m})$ & $\begin{array}{c}\overline{X_{o}-X_{t}} \\
(\mathbf{m m})\end{array}$ & $\begin{array}{c}\overline{Y_{o}-Y_{t}} \\
(\mathrm{~mm})\end{array}$ & $\begin{array}{c}\overline{Z_{o}-Z_{l}} \\
(\mathrm{~mm})\end{array}$ & $\begin{array}{c}S D_{X_{o}-X_{i}} \\
(\mathbf{m m})\end{array}$ & $\begin{array}{c}S D_{Y_{o}-Y_{i}} \\
(\mathrm{~mm})\end{array}$ & $\begin{array}{c}S D_{Z_{o}-Z_{i}} \\
(\mathbf{m m})\end{array}$ & $\mathbf{N}$ \\
\hline$\overline{\mathrm{ABUZ}}$ & 6203493.8010 & 833088.7548 & 1225614.6820 & -17.8189 & 41.3750 & 37.7393 & 13.0201 & 20.3924 & 17.5100 & 1005 \\
\hline BKFP & 6211960.3270 & 459365.5362 & 1368115.0950 & -17.2406 & 43.9483 & 37.6969 & 13.0083 & 22.3079 & 17.6362 & 1007 \\
\hline CLBR & 6287174.1940 & 922979.5159 & 546713.8227 & -4.6045 & 34.8808 & 30.2730 & 16.5738 & 16.1857 & 12.9593 & 619 \\
\hline FUTY & 6145058.4730 & 1362078.9340 & 1029389.9630 & -20.7905 & 43.2734 & 37.5327 & 15.9038 & 21.8792 & 17.6508 & 913 \\
\hline OSGF & 6246471.2440 & 820848.7822 & 994267.9724 & -10.0943 & 31.0638 & 30.4484 & 13.5637 & 16.9034 & 15.5341 & 738 \\
\hline ULAG & 6326097.2870 & 375576.1522 & 719131.7258 & -10.0596 & 32.5199 & 25.5479 & 13.4600 & 13.7330 & 10.2513 & 609 \\
\hline UNEC & 6284298.2910 & 827900.5683 & 708988.6337 & -14.2956 & 41.6940 & 35.6072 & 15.8399 & 21.3134 & 16.7709 & 901 \\
\hline
\end{tabular}


that all the stations were established using the same standard by the same personnel.

\section{Sufficiency and Adequacy of the CORS Data Archive}

On the performance evaluation, the stations are expected to have a long time series of continuous stable measurements with as few disruptions as possible. Table 6 shows the selected IGS station, the number of downloaded observations and the percentage number of unprocessed daily observations. From the table, the number of days with missing observations at BJCO ranged from 3 days in 2014 to 117 days in 2012 . Although, determining the reasons for these disruptions in the BJCO is not within the scope of this research, however, it is evident that it falls short of the IGS guidelines for data sufficiency and adequacy. The only periods with unprocessed observations were $2012(2.8 \%)$ and $2014(0.3 \%)$. This proves the good quality of the RINEX files downloaded from BJCO with the outcome of a high success rate in the processing.

Table 7 shows the NIGNET stations and the data count of downloaded and processed daily observations while Table 8 shows the NIGNET stations, their attributes and the percentage number of unprocessed daily observations. In the year 2011, virtually none of the files downloaded from NIGNET were unprocessed. In the subsequent years, the unprocessed observations were $2.8 \%$ (2012), $2.8 \%$ (2013) and $21.9 \%$ (2014). These unprocessed observations were due to single frequency data contained in the RINEX files downloaded from the NIGNET portal. The reason for this issue with the RINEX files might be attributed to receiver malfunctions, poor station maintenance or issues with data collection and handling. It is also possible that there were configuration issues in some of the RINEX files created by OSGOF. Within the period under study, the total number of NIGNET data files successfully processed ranged from $78.08 \%$ in 2014 to $99.95 \%$ in 2011. However, virtually all the data files from BJCO were

Table 6: The selected IGS station, the number of downloaded observations and the percentage number of unprocessed daily observations.

\begin{tabular}{lcrrrr}
\hline \multicolumn{1}{c}{ Statistic } & Station & $\mathbf{2 0 1 1}$ & $\mathbf{2 0 1 2}$ & $\mathbf{2 0 1 3}$ & $\mathbf{2 0 1 4}$ \\
\hline $\begin{array}{l}\text { No. of Downloaded } \\
\begin{array}{l}\text { Observations (Days) } \\
\text { \% no. of unprocessed } \\
\text { daily observations }\end{array}\end{array}$ & BJCO & 299 & 248 & 332 & 362 \\
\hline$* 1$ s January -10 th November, 2016 & 0.0 & 2.8 & 0.0 & 0.3 \\
\hline
\end{tabular}

*1st January - 10th November, 2016 successfully processed. The two most severe cases of unprocessed data in NIGNET occurred in 2014 at ULAG 99.7\% (348 unprocessed files) and in 2014 at UNEC - 34.2\% (125 unprocessed files).

Fig. 9 shows the average number of downloaded and processed observations from 2011-2014 for all stations. The sufficiency and adequacy of the network was also assessed based on the Intergovernmental Committee on Surveying and Mapping (ICSM) guidelines which states that Tiers 1 and 2 CORS should have less than $9 \mathrm{hr} /$ year $(<1$ day/year) of data outage; while for Tier 3 CORS, data outage should be less than $44 \mathrm{hr} /$ year ( 2 days/year).

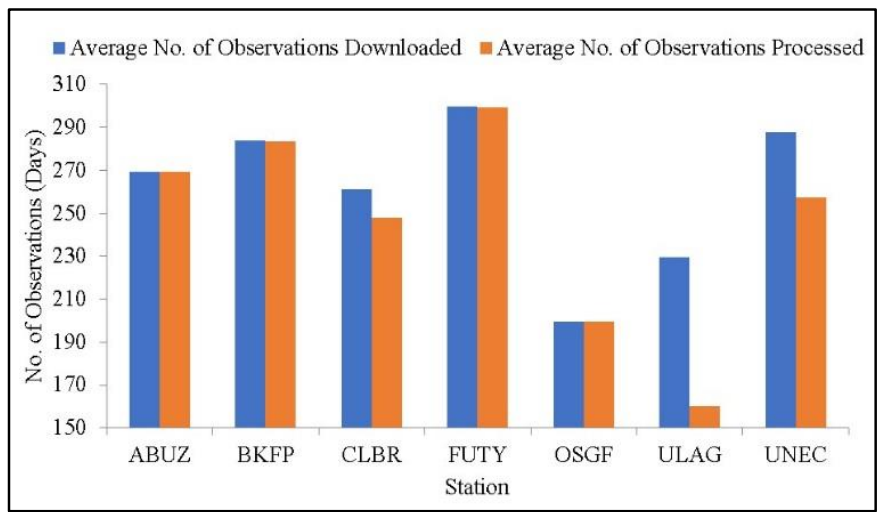

Fig. 9: Average number of downloaded and processed observations for all stations.

Table 9 shows the percentage number of data outages recorded at the NIGNET stations based on the original downloaded data count of daily observations from 2011 2014. Apart from CLBR, which had $90.1 \%$ daily outages in 2011, the other NIGNET stations showed a fairly robust data archival for 2011. For example, on a daily average, ABUZ, BKFP and CGGT had no outages in 2011. However, the trend in NIGNET shows a decrease in the completeness of the data over time. For example, the daily outages at FUTY increased from $1.1 \%$ in 2011 to $20.8 \%$ in 2014 . Surprisingly, OSGF which is located at the NIGNET Control Centre within the headquarters of OSGOF in Abuja had an alarming 74.2\% of data outages in 2014.

Table 7: The selected NIGNET stations and the data count of downloaded and processed daily observations.

\begin{tabular}{|c|c|c|c|c|c|c|c|c|}
\hline \multirow{2}{*}{$\begin{array}{c}\text { Station } \\
\text { Code }\end{array}$} & \multicolumn{4}{|c|}{ No. of Downloaded Observations (Days) } & \multicolumn{4}{|c|}{ No. of Processed Observations (Days) } \\
\hline & 2011 & 2012 & 2013 & 2014 & 2011 & 2012 & 2013 & 2014 \\
\hline ABUZ & 365 & 366 & 355 & 350 & 365 & 366 & 355 & 350 \\
\hline BKFP & 365 & 366 & 339 & 365 & 365 & 366 & 339 & 365 \\
\hline CLBR & 36 & 363 & 340 & 355 & 36 & 292 & 340 & 355 \\
\hline FUTY & 361 & 330 & 361 & 289 & 360 & 330 & 361 & 287 \\
\hline OSGF & 299 & 363 & 335 & 94 & 299 & 363 & 335 & 94 \\
\hline ULAG & 301 & 364 & 364 & 349 & 301 & 364 & 295 & 1 \\
\hline UNEC & 362 & 366 & 364 & 365 & 362 & 366 & 364 & 240 \\
\hline Total & 2089 & 2518 & 2458 & 2167 & 2088 & 2447 & 2389 & 1692 \\
\hline
\end{tabular}

*1st January - 10th November, 2016 
Table 8: The selected NIGNET stations, their attributes and the percentage number of unprocessed daily observations.

\begin{tabular}{|c|c|c|c|c|c|c|c|c|}
\hline \multirow{2}{*}{$\begin{array}{c}\text { Station } \\
\text { Code }\end{array}$} & \multirow[t]{2}{*}{ Latitude (degree) } & \multirow[t]{2}{*}{ Longitude (degree) } & \multirow[t]{2}{*}{ Ellipsoidal height (m) } & \multirow[t]{2}{*}{ Location } & \multicolumn{4}{|c|}{ \% No. of Unprocessed Observations } \\
\hline & & & & & 2011 & 2012 & 2013 & 2014 \\
\hline ABUZ & 11.15 & 7.65 & 706.1 & Zaria & 0.0 & 0.0 & 0.0 & 0.0 \\
\hline BKFP & 12.47 & 4.23 & 251.0 & Birnin Kebbi & 0.0 & 0.0 & 0.0 & 0.0 \\
\hline CLBR & 4.95 & 8.35 & 61.5 & Calabar & 0.0 & 19.6 & 0.0 & 0.0 \\
\hline FUTY & 9.35 & 12.50 & 248.4 & Yola & 0.3 & 0.0 & 0.0 & 0.7 \\
\hline OSGF & 9.03 & 7.49 & 533.6 & Abuja & 0.0 & 0.0 & 0.0 & 0.0 \\
\hline ULAG & 6.52 & 3.40 & 45.5 & Lagos & 0.0 & 0.0 & 19.0 & 99.7 \\
\hline UNEC & 6.42 & 7.50 & 255.4 & Enugu & 0.0 & 0.0 & 0.0 & 34.2 \\
\hline & & Total & & & 0.0 & 2.8 & 2.8 & 21.9 \\
\hline
\end{tabular}

*1st January - 10th November, 2016

Table 9: Percentage number of data outages recorded at the NIGNET stations based on the original downloaded data count of daily observations from $2011-2015$.

\begin{tabular}{|c|c|c|c|c|c|c|c|}
\hline \multirow[t]{2}{*}{ Station Code } & \multicolumn{4}{|c|}{ Percentage no. of data outages (days/year) } & \multirow[t]{2}{*}{ Tiers 1 and 2 standard } & \multirow[t]{2}{*}{ Tier 3 standard } & \multirow[t]{2}{*}{ Remark } \\
\hline & 2011 & 2012 & 2013 & 2014 & & & \\
\hline $\mathrm{ABUZ}$ & 0.0 & 0.0 & 2.7 & 4.1 & $\mathrm{x}$ & $\mathrm{x}$ & Not adequate for Tiers $1-3$ \\
\hline BKFP & 0.0 & 0.0 & 7.1 & 0.0 & $\mathrm{x}$ & $\mathrm{x}$ & Not adequate for Tiers $1-3$ \\
\hline CLBR & 90.1 & 0.8 & 6.8 & 2.7 & $\mathrm{x}$ & $\mathrm{x}$ & Not adequate for Tiers $1-3$ \\
\hline FUTY & 1.1 & 9.8 & 1.1 & 20.8 & $\mathrm{x}$ & $\mathrm{x}$ & Not adequate for Tiers $1-3$ \\
\hline OSGF & 18.1 & 0.8 & 8.2 & 74.2 & $\mathrm{x}$ & $\mathrm{x}$ & Not adequate for Tiers $1-3$ \\
\hline ULAG & 17.5 & 0.5 & 0.3 & 4.4 & $\mathrm{x}$ & $\mathrm{x}$ & Not adequate for Tiers $1-3$ \\
\hline UNEC & 0.8 & 0.0 & 0.3 & 0.0 & $\mathrm{x}$ & $\mathrm{x}$ & Not adequate for Tiers $1-3$ \\
\hline
\end{tabular}

Despite the observed disruptions in the data from BJCO, the IGS data are still more consistent and well distributed over the time period under consideration. At no point was BJCO offline almost all year round as in the case of some NIGNET stations. This points to the fact that the IGS stations are well monitored and better maintained than NIGNET.

Table 10 presents the summary of the performance evaluation of the COR stations based on the IGS and international standards to further answer the question relating to adequacy/sufficiency of the network for the definition and realisation of the Nigerian reference frame. Obviously, while the accuracy analysis suggests a good data quality based on the realisation of a geocentric datum for Nigeria and contribution to AFREF and the IGS network in general). Unfortunately, a station such as ULAG located at the commercial hub of the nation, which could have been of immense benefit to the larger society for diverse applications is currently not acquiring data. Consequently, there is no data streaming from the station. Investigation conducted on this site revealed that the major cause of the problem is a faulty antenna, and there is currently no plan on ground to address the problem. Generally, given that the typical lifespan of CORS is 20 years, efforts must be concerted to ensure the smooth running of this invaluable infrastructure, otherwise, the sustainability of the project cannot be guaranteed.

Table 10: Summary of the performance evaluation across the stations.

\begin{tabular}{|c|c|c|c|c|c|c|c|}
\hline Evaluation Criteria & ABUZ & BKFP & CLBR & FUTY & OSGF & ULAG & UNEC \\
\hline Choke ring antenna for Tier $1 / 2$ & $\sqrt{ }$ & $\sqrt{ }$ & $\sqrt{ }$ & $\sqrt{ }$ & $\sqrt{ }$ & $\sqrt{ }$ & $\sqrt{ }$ \\
\hline Minimum spacing of $70 \mathrm{~m}$ & $\mathrm{x}$ & $\mathrm{x}$ & $\mathrm{x}$ & $\mathrm{x}$ & $\mathrm{x}$ & $\mathrm{x}$ & $\mathrm{x}$ \\
\hline Data quality & $\sqrt{ }$ & $\sqrt{ }$ & $\sqrt{ }$ & $\sqrt{ }$ & $\sqrt{ }$ & $\sqrt{ }$ & $\sqrt{ }$ \\
\hline $\begin{array}{l}\text { Sufficiency/ } \\
\text { adequacy }\end{array}$ & $\mathrm{x}$ & $\mathrm{x}$ & $\mathrm{x}$ & $\mathrm{x}$ & $\mathrm{x}$ & $\mathrm{x}$ & $\mathrm{x}$ \\
\hline Infra- structural support & $\mathrm{x}$ & $\mathrm{x}$ & $\mathrm{x}$ & $\mathrm{x}$ & $\mathrm{x}$ & $\mathrm{x}$ & $\mathrm{x}$ \\
\hline Data recording interval (30s) & $\sqrt{ }$ & $\sqrt{ }$ & $\sqrt{ }$ & $\sqrt{ }$ & $\sqrt{ }$ & $\sqrt{ }$ & $\sqrt{ }$ \\
\hline Continuity in data acquisition & $\sqrt{ }$ & $\sqrt{ }$ & $\sqrt{ }$ & $\sqrt{ }$ & $\sqrt{ }$ & $\mathrm{x}$ & $\sqrt{ }$ \\
\hline Monument rigidity & $\sqrt{ }$ & $\sqrt{ }$ & $\sqrt{ }$ & $\sqrt{ }$ & $\sqrt{ }$ & $\sqrt{ }$ & $\sqrt{ }$ \\
\hline Minimum power interruption & $\mathrm{x}$ & $\mathrm{x}$ & $\mathrm{x}$ & $\mathrm{x}$ & $\mathrm{x}$ & $\mathrm{x}$ & $\mathrm{x}$ \\
\hline Internet connectivity & $\mathrm{x}$ & $\mathrm{x}$ & $\mathrm{x}$ & $\mathrm{x}$ & $\mathrm{x}$ & $\mathrm{x}$ & $\mathrm{x}$ \\
\hline Combination of techniques & N/A & N/A & N/A & N/A & N/A & N/A & N/A \\
\hline
\end{tabular}

NB: $\sqrt{ }$ - within the recommendation, $x$ - below the recommendation, N/A - Not Available

average of $20 \mathrm{~mm}$ standard deviations, there remains a lot to be done in many aspects particularly at the infrastructural level that include the collocation of different techniques of data acquisition, continuous power supply and internet connectivity, if NIGNET must fulfil its mandate (i.e. the

\section{CONCLUSIONS}

This study examined the temporal stability and the quality of NIGNET data using precise point positioning and time series analysis techniques. The study showed a relative stability required for Tiers 1 and 2 CORS in line with the IGS 
standards. However, the coordinates of the stations in NIGNET require constant monitoring to ensure reliable and accurate positioning. This can help to detect changes in antenna positions caused by human or natural effects. A methodology has been established that could be used in future studies to monitor such changes as well as to evaluate the adequacy of NIGNET to define the geodetic reference frame (GRF) for Nigeria. This constitutes a significant contribution. Although, more stations are needed to densify NIGNET, it is imperative that the existing stations are well maintained to ensure the maximum utility of their products in the time being. OSGOF should also liaise with research institutions in developing software and models to account and correct for changes in station positions caused by local geologic distortions and crustal displacements.

Given the objective of NIGNET following its establishment, it is unfortunate that the stations have been plagued by many problems to compromise the standard. For example, some of the antennas have malfunctioned and can no longer track both L1 and L2 frequencies, while the internet connection at many of the stations is unstable. The problem of data streaming has been a major concern due to unavailability of internet connection. The current problems have significant effect on the availability of accurate and reliable information relating to the position and uncertainty of NIGNET, which is critical to the integrity of the nation's Geodetic Reference Frame in accordance with the IGS guidelines. Also, a variety of unification issues must be considered in the future establishment of CORS, and the coordination of CORS established by different sectors such as states and private companies to meet numerous needs.

Presently, it is evident that the Federal Government through OSGOF is unable to maintain NIGNET at optimum operational condition all year round. The recent economic recession in Nigeria coupled with dwindling allocations from the Federal Government to ministries and agencies have worsened the situation. It is therefore advisable to redirect financial resources earmarked for the establishment of new CORS to maintaining the existing network. Also, positioning data from NIGNET should be well marketed to public users. This will ensure funds are generated for the maintenance of the network. More importantly, it must be noted that the management of a national CORS network should not be the sole responsibility of the government as the case in the developed nations such as the United States. Lastly, it is noted that the upgrade of NIGNET to a real-time kinematic GNSS network remains an important objective.

\section{ACKNOWLEDGEMENTS}

The authors are grateful to the Office of the Surveyor General of the Federation (OSGOF), Nigeria for the access granted to the NIGNET data. We also acknowledge the efforts of Mr. Omeiza Mayaki for his assistance with the data processing using GAPS.

\section{REFERENCES}

Ayodele, E.G; C.J. Okolie; C.U. Ezeigbo and F.A. Fajemirokun. (2017). Evaluation of Continuously Operating Stations (CORS) Data for the Definition of Nigerian Geodetic Reference Frame. Nigerian Association of Geodesy General Assembly/Conference. Port-Harcourt, 1-21.

Andrei, C.O; D. Salazar and R. Chen. (2010). Performance Analysis of the Precise Point Positioning Technique at BUCU IGS Station. RevCAD - Journal of Geodesy and Cadastre, 10: 9-20.

Burns, D. and Sarib, R. (2010). Standards and Practices for GNSS CORS Infrastructure, Networks, Techniques and Applications. FIG Congress 2010. Sydney, Australia, 11-16.

Cai, C. (2009). Precise Point Positioning using DualFrequency GPS and GLONASS Measurements. M.Sc. Thesis. University of Calgary. UCGE Reports. Number 20291.

Crawley, M.J. (2005). Statistics: An Introduction to R. England: Wiley.

Daniels, M.Y. (1973). A History of Triangulation in Nigeria, M.Sc. Thesis, Dept. of Surveying, University of Lagos, Lagos.

Dawidowicz, K. and Krzan, G. (2014). Coordinate Estimation Accuracy of Static Precise Point Positioning using Online PPP Service - A case study. Acta Geodetica et Geophysica Hungarica, 49(1): 37-55.

Ezeigbo, C.U. (2007). The Role of Geodesy in Nigeria's Space Program. Proceedings of the Nigerian Association of Geodesy (NAG) Conference, 59-70.

Fajemirokun, F.A. (2006). Geodesy in Nigeria: Past, Present and Future (Union Lecture I). Paper presented at the 2006 Nigerian Association of Geodesy (NAG) Conference, University of Lagos, Nigeria, 23rd - 25th August, 1-20.

Fajemirokun, F.A. (2009). Benefits of GNSS/AFREF NIGNET Project. Presented at the International Awareness Conference on CORS using GNSS, Abuja 2009, 1-25.

Field, N.J. (1977). Adjustment and Strength Analysis of the Primary Triangulation Network of Nigeria, M. Phil Thesis, University of Nottingham, England.

Gao, Y. and Chen, K. (2004). Performance Analysis of Precise Point Positioning Using Real-Time Orbit and Clock Products. Journal of Global Positioning Systems, 3(1-2): 95100.

Gao, Y; K. Chen and X. Shen. (2003). Real-Time Kinematic Positioning based on Undifferenced Carrier Phase Data Processing. Proceedings of ION NTM-2003, Jan.22 -24, 2003, Anaheim, California, 362-368.

Grejner-Brzezinska, D.A. (2009). Mapping and Surveying. Presented at the First Workshop on Satellite Navigation Science and Technology for Africa, Abdus Salam International Centre for Theoretical Physics, Trieste, Italy, March 31, 1-215.

Hale, M.J; P.A. Collier; A.M. Kealy; P.J. Ramm and J.C. Millner. (2006). Validating a Model for CORS Network Management. Proceedings of the IGNSS 2006 Symposium, 114.

Huber, K; F. Heuberger; C. Abart; A. Karabatic; R. Weber and P. Berglez. (2010). PPP: Precise Point Positioning 
- Constraints and Opportunities. FIG Congress 2010, Sydney, Australia, 11-16 April 2010, 1-17.

ICSM (2014). Guideline for Continuously Operating Reference Stations Special Publication 1, Version 2.1. Intergovernmental Committee on Surveying and Mapping (ICSM) - Permanent Committee on Geodesy

IGS (2015). Current IGS Site Guidelines. Retrieved from the International GNSS Service, IGS website. https://kb.igs.org/hc/en-us/articles/202011433-Current-IGSSite-Guidelines/ (Date accessed - 30 Aug, 2017).

IGS (2017). Site Guidelines Clarifications. Retrieved from the International GNSS Service, IGS website. https://kb.igs.org/hc/en-us/articles/203840328/ (Date accessed - 30 Aug, 2017).

Iyiola, F; R. Ogundele; C. Oluwadare and O. Kufoniyi. (2013). Integrity Check on Ground Control Points Using NIGNET's Continuously Operating Reference Stations. FIG Working Week 2013, Abuja, Nigeria, 6 - 10 May 2013, 1-13.

Janssen, V. (2009). How to Establish an AusCORS site. Position, 44: 64-66.

Kouba, J. and Héroux, P. (2001). Precise Point Positioning using IGS Orbit and Clock Products. GPS Solutions, 5(2): 12-28.

Leandro, R.F; M.C. Santos and R.B. Langley. (2007). GAPS: The GPS Analysis and Positioning Software - A Brief Overview. ION GNSS 20th International Technical Meeting of the Satellite Division, 25-28, September 2007, Fort Worth, TX.

Leandro, R.F; M.C. Santos and R.B. Langley. (2010). Analysing GNSS data in Precise Point Positioning Software. GPS Solutions, 15: 1-13.

Lechner, W. and Baumann, S. (2000). Global Navigation Satellite Systems. Computers and Electronics in Agriculture, 25: $67-85$

LPI (2012). Guidelines for CORSnet-NSW Continuously Operating Reference Stations (CORS), version 1.1. NSW Government - Land and Property Information.

Mayaki A.O; T. Nikolaidou; M. Santos and C.J. Okolie. (2018). Comparing the Nigerian GNSS Reference Network's Zenith Total Delays from Precise Point Positioning to a Numerical Weather Model. In: Freymueller J., Sánchez L. (eds) International Symposium on Advancing Geodesy in a Changing World. International Association of Geodesy Symposia, vol 149. Springer, Cham.

NOAA (2013). Guidelines for New and Existing Continuously Operating Reference Stations (CORS). National Geodetic Survey - National Ocean Survey, NOAA, 1-21.

Nwilo, P.C; C.J. Okolie and C.U. Onwuzuligbo. (2016). Technological Advancements in Geodetic Infrastructure: The Nigerian Adaptation. Paper presented at the Nigerian Association of Geodesy 2016 General Assembly/Conference, Enugu Nigeria, 1-15.
Ogwude, G.N. (1974). Evaluation of Astronomical Observations in Nigeria, M.Sc. Thesis, Dept. of Surveying, University of Lagos.

Omoigui, D.A. and Fadahunsi, O. (1980). The Nigerian Triangulation System: Design, Observations and Adjustment Problems, Paper presented at the Seminar Series on Surveying and Mapping in Nigeria, Dept. of Surveying, University of Lagos.

Omoigui, D.A. (1973). The Nigerian Triangulation and the Scale Check Programme, Proceedings of the International Seminar on Electronic Distance Measurements, University of Lagos, Lagos.

OSGOF (2012). Report on NIGNET GNSS Data Processing 2010 - 2011.

Ovstedal, O; N.S. Kjorsvik and J.G.O. Gjevestad. (2006). Surveying using GPS Precise Point Positioning. XXIII FIG Congress, Munich, Germany, October 8-13, 2006, 1-10.

Pace B; R. Pacione; C. Sciarretta and G. Bianco. (2015). Computation of Zenith Total Delay Correction Fields Using Ground-Based GNSS. In: Sneeuw N., Novák P., Crespi M., Sansò F. (eds) VIII Hotine-Marussi Symposium on Mathematical Geodesy. International Association of Geodesy Symposia, vol 142. Springer, Cham.

R Core Team. (2017). R: A language and environment for statistical computing. R Foundation for Statistical Computing. Vienna, Austria. Available at: https://www.R-project.org

Schwieger, V; M. Lilje and R. Sarib (2009). GNSS CORS - Reference Frames and Services. International Federation of Surveyors (FIG), Article of the Month December 2009, 1-21.

Snay, R.A. and Soler, T. (2008). Continuously Operating Reference Station CORS: History, Applications, and Future Enhancements. Journal of Surveying Engineering, 134(4): 95104.

Soler, T; R.A. Snay; R.H. Foote and M.W. Cline. (2003). Maintaining Accurate Coordinates for the National CORS Network. FIG Working Week 2003, Paris, France, April 1317, 1-8.

TAMU (2017). GPS Basics. Texas A \& M University website.

http://www.math.tamu.edu/ dallen/physics/gps/gps.htm/ (Date accessed - 28 Aug, 2017)

Tomasz, H (2015). GNSS-Warp Software for Real-Time Precise Point Positioning. Artificial Satellites, 50(2) - 2015.

UNSW (2017). What is a CORS Network? The University of New South Wales website. http://www.sage.unsw.edu.au/currentstudents/ug/projects/Go wans/Thesis/What is it.html/ (Date accessed - 28 Aug, 2017)

Zumberge, J.F; M.B. Heflin; D.C. Jefferson; M.M. Watkins and F.H. Webb. (1997). Precise Point Positioning for the Efficient and Robust Analysis of GPS Data from large networks. Journal of Geophysical. Research, 102(B3): 50055018. 